
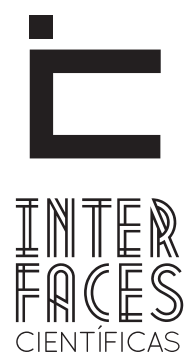

EDUCAÇÃO

ISSN IMPRESSO 2316-333X

ISSN ELETRÔNICO 2316-3828

Dossiê

\title{
AOS PÉS DA ÁGUIA ALADA: OS GRUPOS ESCOLARES E A INFÂNCIA SERGIPANA NOS TEMPOS DE GRACCHO CARDOSO [1922-1926]
}

Magno Francisco de Jesus Santos ${ }^{1}$

\section{RESUMO}

No alvorecer do século XX, em Sergipe, os republicanos buscaram redefinir os traços das principais cidades do estado, embelezando-as e dotando-as de construções imponentes. O objetivo deste artigo é compreender o discurso dos grupos escolares criados em Sergipe no governo Graccho Cardoso (1922-1926) e os discursos acerca da formação da infância sergipana. Realizamos uma análise acerca do processo de implantação desse modelo de instituição por meio de documentos escritos e iconográficos e dos aspectos que intervieram nesse processo. Assim eclodiram os monumentos que embelezaram as cidades sergipanas e tentaram forjar uma identidade republicana respaldada pelo processo civilizatório.

\section{PALAVRAS-CHAVE}

Educação primária. Infância. Arquitetura escolar. 


\section{ABSTRACT}

At the dawn of the twentieth century, in Sergipe, Republicans sought to redefine the traits of the main cities of the state, embellishing them and providing them with imposing buildings. The objective of this paper is to understand the discourse of school groups created in Sergipe Graccho Cardoso government (1922-1926) and discourses about the formation of Sergipe childhood. An analysis about the deployment of this model institution through written and iconographic documents and aspects that participated in this process. Thus hatched the monuments that graced the Sergipe cities and tried to forge an identity backed by Republican civilizing process.

\section{KEYWORDS}

Primary education. Childhood. School architecture.

\section{RESUMEN}

En los albores del siglo XX, en Sergipe, los republicanos trataron de redefinir las características de las principales ciudades del estado, embellecer ellos y proporcionándoles imponentes edificios. El objetivo de este trabajo es entender el discurso de los grupos escolares creados en el gobierno de Sergipe Graccho Cardoso (1922-1926) y los discursos sobre la formación de Sergipe infancia. Un análisis sobre la implementación de esta institución modelo a través de documentos y aspectos escritos e iconográficos que participaron en este proceso. Así eclosionado los monumentos que adornaban las ciudades de Sergipe y trataron de forjar una identidad respaldada por proceso civilizador republicano.

\section{PALABRAS CLAVE}

Eucación primaria. La infancia. La arquitectura escolar. 


\section{INTRODUÇÃ̃}

Prédios monumentais. Edifícios públicos erguidos nos centros das principais cidades sergipanas. Arquitetura voltada para a ação pedagógica. Templos destinados ao culto da República. Eram os imponentes prédios dos grupos escolares, criados ao longo dos primeiros decênios do século XX e que no governo de Graccho Cardoso atingiu seu ápice. Em quatro anos a paisagem urbana de Aracaju e das principais cidades do interior sergipano passaram por profundas transformações. A arquitetura monumental passou a exercer o poder de clamar a atenção dos transeuntes.

Os primeiros grupos escolares de Sergipe foram construídos na segunda década do século $X X$, nas administrações estaduais de Rodrigues Dórea, General Siqueira de Menezes e Oliveira Valladão. Eram os primeiros edifícios do estado voltados para o ensino público primário. Todavia, foi no período de Graccho Cardoso (1922-1926), que a escola graduada foi disseminada com maior vigor. Ao todo, foram 16 prédios escolares inaugurados tanto na capital como no interior. Todos eles eram marcados pela magnitude arquitetônica. Eram monumentos públicos destinados à instrução da infância sergipana.

\section{SOB 0 OLHAR ATENTO DA ÁGUIA: A DIFUSÃO DOS GRUPOS ESCOLARES}

A maior disseminação dos grupos escolares em Sergipe ocorreu no governo de Graccho Cardoso (1922-1926). Aproveitando-se da estabilidade econômica do estado e das construções não concluídas pela gestão que o antecedeu, de Pereira Lobo, ele promoveu um chorrilho de inaugurações das ilhas de modernidade pelos mais diversos municípios. A capital foi a cidade que deteve maior atenção do presidente, com a construção de inúmeros prédios escolares, além de novas instituições científicas, sociais e de saúde pública.
O processo de inaugurações executado por Graccho Cardoso teve início na cidade de Estância, com a criação do Grupo Escolar Gumersindo Bessa. No mesmo ano foi inaugurada a escola graduada de São Cristóvão. Foi a criação do Grupo Vigário Barroso², que ocupou o prédio da antiga prisão. Com isso, a velha capital também passava a ser beneficiada com o ensino primário graduado, a contar com uma escola racionalizada e moderna, que poderia preparar os alunos para que se tornassem civilizados e aptos para o trabalho urbano, especialmente o fabril.

Em 1924 foram construídos mais dois prédios escolares, sendo um na capital e o outro no interior. 0 do interior foi o Grupo Escolar Sílvio Romero, na cidade de Lagarto. Com uma construção imponente, a cidade passou a desfrutar das benesses da ilha de civilização que adentrava os municípios do interior sergipano. Já o primeiro, não se tratava de um novo grupo escolar, mas apenas uma readaptação. Dois grupos escolares da capital tiveram que ser transferidos para novos prédios, motivados pela instalação do batalhão da polícia militar e de uma faculdade ${ }^{3}$. Assim alegou 0 governo de Graccho Cardoso:

Devido à premente necessidade, no Grupo Escolar General Siqueira foi alojado o Batalhão Policial Militar do Estado, dada a imprestabilidade do quartel então existente, o governo já contractou, porém, com o constructor Hugo Bozzi, a elevação de um novo prédio em

2. Pereira Lobo cogitou a implantação de um grupo escolar na primeira capital de Sergipe, São Cristóvão. Todavia, os planos de Lobo divergiram em alguns aspectos da idéia concretizada por Graccho Cardoso.

3.Graccho Cardoso tentou implantar o ensino superior em Sergipe com a criação de duas faculdades e um instituto. As faculdades foram instaladas provisoriamente nos melhores prédios públicos da cidade, ou seja, nos edifícios onde funcionavam os grupos escolares. Com isso, foram inauguradas a Faculdade de Farmácia e Odontologia Aníbal Freire e a Faculdade Livre de Direito Tobias Barreto, além do Instituto de Química. As três instituições passaram a fomentar os anseios dos sergipanos, de terem instituições de nível superior no estado. Sobre o Instituto de Química de Sergipe pode ser consultado Conceição (2008), que enfoca o processo de implantação e a intelectualidade que fazia parte de seus quadros. Além dessas instituições, existia outra, que inaugurou o ensino superior em Sergipe. Tratava-se do Seminário Sagrado Coração de Jesus, criado em 1913 (BARRETO, 2004). 
substituição àquelle, respeitada em absoluto a antiga denominação, em homenagem ao illustre ex-presidente do Estado. As classes desse grupo foram temporariamente transferidas para o edifício do antigo Grupo General Valladão, hoje em dia Faculdade Livre de Direito Tobias Barretto (SERGIPE, 1925, p. 14)

Entretanto, havia outra justificativa maior para a transferência desses grupos. A proximidade dos prédios estava acarretando na redução do número de alunos matriculados, impedindo a disseminação dos novos pressupostos metodológicos e a consolidação da modernidade pedagógica. Para a administração Graccho Cardoso:

Em razão de se acharem situados mui próximos um do outro, na distancia media talvez de menos de tresentos metros, os grupos escolares General Valladão, Barão de Maroim e General Siqueira, é que foi feita a mudança do primeiro para o edifício construído, o anno transacto, à rua da Victoria. Tal circunstancia implicou ainda para que fosse localizado no edifício em que funccionava o Grupo General Siqueira o Batalhão Policial, havendo para tal utilização recebido as adaptações imprescindíveis. Não tardará que o que lhe vae substituir se erga em logar conveniente (SERGIPE, 1924, p. 14).

A justificativa do presidente nos induz a refletir sobre um problema gerado na implantação dos grupos escolares em Sergipe. Em decorrência da proximidade dos edifícios havia uma distribuição distorcida dos alunos. Devemos lembrar que, uma das características dessa categoria de escola era a localização privilegiada, nas proximidades do centro da cidade. A excessiva proximidade desses prédios escolares resultou na rarefação dos alunos, que ficavam dispersos em três instituições. A eloqüência dos discursos arquitetônicos se proliferava nos arredores do centro da capital, constituindo uma paisagem cercada de palacetes. Nesse sentido, entre os prédios públicos sedes do poder político emergiam os grupos escolares, com a incumbência de atribuir um novo sentido aos transeuntes, de confirmar aos olhares as preocupações do governo no campo da educação.

No ano seguinte, o presidente buscou intensificar o ritmo de inaugurações, concluindo as obras inaca- badas deixadas pelo seu antecessor, o coronel Pereira Lobo. Nisso, novos prédios escolares foram entregues, entre eles o de Vilanova. Estrategicamente, Graccho Cardoso promoveu algumas alterações no projeto do prédio, dotando-lhe de características que remetiam a sua administração. Era uma forma de criticar a gestão anterior e legitimar seu nome como um presidente construtor, empreendedor e condutor da modernidade. Isso acarretou na diminuição estética dos edifícios construídos por Pereira Lobo:

\begin{abstract}
Tendo começado a minha gestão a 24 de Outubro de 1922, inaugurava, em Maio de 1923, o primeiro grupo escolar na cidade de Estância, sob o patronymico de Gumersindo Bessa. Essa obra durou de 1918 aos fins de 1922, sendo pecuniariamente solvido o respectivo contracto na actual administração. Veio logo depois o Grupo Olympio Campos, em Villanova, iniciado também em 1917, para servir de reunião de escolas. Já encontrei acabada a construção desse edifício, que é péssima, limitando-me, simplesmente, a rematar o respectivo acabamento, quando de sua entrega a população (SERGIPE, 1924, p. 14).
\end{abstract}

Sob a batuta de Graccho Cardoso as cidades sergipanas foram transformadas em verdadeiros canteiros de obras, incitando o processo de modernização e de embelezamento que tinha eclodido na década anterior. No cenário urbano emergiam palacetes imponentes que se impunham sobre os logradouros com o olhar vigilante das águias, ${ }^{4}$ prontas para o vôo. Essa ave se tornou símbolo maior das construções realizadas na gestão de Graccho Cardoso, representando a visão profícua e perspicaz. Na mensagem de 1924 o governo enumera as

\footnotetext{
4. A administração de Graccho Cardoso foi marcada pelas polêmicas e gastos onerosos com as obras públicas. Tratou-se de uma gestão que acelerou o processo de auto-propaganda tendo como vitrine as obras. Com isso, percebemos que nos primeiros anos da década de 20 do século $\mathrm{XX}$ as obras estavam imbuídas do sentido de se forjar uma identidade presidente/obra, criador-criatura. Os lugares sociais foram redefinidos, com a reaproximação do Estado em relação a Igreja Católica e construção de grandes edifícios públicas com o designativo de seu governo: a águia. Ela simbolizava a tentativa de constituir uma administração que visualizasse o futuro, que tivesse um olhar de longo alcance. Sobre esse assunto podem ser consultadas obras sugestivas como as de Josineide Santana (2000) e Antônio Samarone Santana (2005).
} 
inaugurações dos novos prédios que abrigariam os grupos escolares.

Foram terminadas as construcções dos grupos escolares “Dr. Manuel Luiz”, General Valladão, e "José Augusto Ferraz", nesta capital, "Severiano Cardoso", em Boquim; o de Simão Dias e as escolas reunidas de Santo Amaro. A concluir-se está o Grupo “Coronel João Fernandes”, em Propriá (SERGIPE, 1924, p. 22).

Como pode ser observado, de imediato Graccho Cardoso buscou inaugurar uma série de prédios que atenderiam ao ensino primário. No total foram onze edifícios construídos na sua gestão, quase todos com um mesmo traçado arquitetônico, marcados pela imponência da fachada e presença das águias. Com isso, na era dos grupos escolares sergipanos ${ }^{5}$, Graccho Cardoso foi o presidente que mais difundiu esse tipo de instituição, a modalidade de escola primária graduada. O perfil majestoso dos prédios que se impunham na paisagem urbana das principais cidades sergipanas, criando ao mesmo tempo imagens de escola como prédio público e de cidade moderna, que progredia com os avanços da educação. 0 imaginário republicano ${ }^{6}$ foi exposto nas pare-

\footnotetext{
5. Sergipe passou por um processo semelhante ao que ocorreu no estado da Paraíba, no que concerne à implantação dos grupos escolares. Segundo Antônio Pinheiro (2002), naquele estado ocorreram três fases, por ele denominadas de eras, na perspectiva de Hobsbawn: a era das cadeiras isoladas, era dos grupos escolares e era das escolas rurais, que não foi aprofundada. Em Sergipe podemos observar um processo semelhante, ao menos se enfocarmos os discursos das autoridades políticas, pois até 1911 teríamos a era das escolas isoladas. Entre 1911 e o final da década de 20 do século $X X$ seria a era dos grupos escolares. A partir desse período até o final dos anos 40 do século XX Sergipe estaria na era das escolas rurais. Devemos lembrar que essa divisão temporal tem como enfoque apenas a ênfase dada nos discursos das lideranças políticas e educacionais, pois na prática vimos que nessas três fases ocorreu a expansão das escolas isoladas.

6. Nos anos imediatos à Proclamação da República verificou-se um processo de embates entre as diferentes ramificações republicanas que tentavam se impor no cenário político nacional. Eram vertentes que tinham influência do federalismo americano, do positivismo e dos jacobinos. Para compreender esse imaginário construído com o golpe da República pode ser consultada as instigantes obras de José Murilo de Carvalho $(1990,1996)$ e Raquel Barbosa, que subsidiada pela reflexão de Carvalho observa a construção dos heróis literários nas escolas paulistas (BARBOSA, 2001).
}

des dos prédios escolares. Os projetos dos grupos não eram apenas de uma escola racionalizada, mas também um desígnio de um país que buscava exasperadamente planear a civilização?

O governo de Graccho Cardoso marcou o apogeu e o declínio da difusão dos grupos escolares em Sergipe. Após a sua gestão ocorreu mais um lapso no processo de propagação desse modelo de instituição e com o retorno, na década seguinte as características arquitetônicas já não eram as mesmas. A racionalidade tinha sido fortalecida e o traçado tornou-se mais simples, excluindo a ornamentação neoclássica. A imponência tinha sido reduzida bruscamente ${ }^{8}$. No período compreendido entre 1911 e 1926 foram inaugurados 14 grupos e 16 prédios escolares, com características monumentais. As obras foram financiadas pelo governo do estado ou fruto de doações de particulares ou campanhas educacionais. Os grupos criados nesse período encontram-se relacionados no Quadro I:

\footnotetext{
7. O termo civilização aparece em muitos registros documentais da época quase sempre associados à idéia de transformação da sociedade brasileira por meio do combate aos maus-costumes e ao analfabetismo. Para a intelectualidade da época, assim como as lideranças político-administrativas do estado de Sergipe, os maiores problemas que impediam o ingresso do país no mundo civilizado era a ignorância da população, prisioneira dos maus-costumes e a ausência de escolas para o combate a esses vícios. Outra situação que era alvo das críticas dos presidentes de Sergipe era a ineficiência do professorado, que despreparado e sem dedicação ao ensino cravavam novos empecilhos na construção da civilização brasileira. O desleixo com assiduidade e ausência de afinco na tarefa de ensinar. Em 1924 o presidente de Sergipe Maurício Graccho Cardoso expôs sua preocupações com o elevado número de professores que entravam com pedidos de licença, alegando que "Na maioria das vezes ficam essas cadeiras por muito tempo sem provimento, estabelecendo-se assim solução médicos graciosos, que são desmentidos não só pelo aspecto sadio das solicitantes, como pela vida que levam aqui na capital ou em outros logares, durante o goso da licença" (SERGIPE, 1924 , p. 40).

8. Como os grupos escolares construídos após o governo de Graccho Cardoso foram marcados pela presença de traços mais simples a destoarem do padrão das edificações anteriores, resolvemos não inserir os mesmos no presente estudo. Nessa fase os grupos foram construídos em cidades que ainda não usufruíam dessa modalidade de ensino, com a reunião de escolas isoladas em um mesmo prédio, como já havia essa cogitação desde a década de 10 do século XX. Cidades como Itabaiana, Riachuelo, Itaporanga d'Ajuda e Laranjeiras passaram a ter seus respectivos grupos escolares. Sobre a implantação do Grupo Escolar Guilhermino Bezerra de Itabaiana pode ser lido o texto de Hosenilde Lima (2005).
} 
QUADRO I

Relação dos prédios dos grupos escolares de Sergipe criados entre 1911-1924

\begin{tabular}{|c|c|c|c|c|}
\hline Ano de inauguração & Nome da instituição & Cidade & $\begin{array}{l}\text { Governo em que foi } \\
\text { construído }\end{array}$ & Origem do prédio/terreno \\
\hline 1911 & Grupo Modelo & Aracaju & Rodrigues Dória & Escola Normal, construída pelo Estado \\
\hline 1914 & Grupo Central & Aracaju & $\begin{array}{l}\text { General Siqueira de } \\
\text { Menezes }\end{array}$ & $\begin{array}{l}\text { Construído pelo Estado para o } \\
\text { próprio fim }\end{array}$ \\
\hline 1917 & $\begin{array}{l}\text { Grupo Escolar Barão de } \\
\text { Maroim }\end{array}$ & Aracaju & $\begin{array}{l}\text { General Oliveira } \\
\text { Valadão }\end{array}$ & $\begin{array}{l}\text { Construído pelo Estado no terreno } \\
\text { doado pelo Barão de Maruim }\end{array}$ \\
\hline 1918 & $\begin{array}{l}\text { Grupo Escolar General } \\
\text { Valladão }\end{array}$ & Aracaju & $\begin{array}{l}\text { General Oliveira } \\
\text { Valadão }\end{array}$ & $\begin{array}{l}\text { Construção financiada por } \\
\text { campanha realizada pelos sócios } \\
\text { do Comício Agrícola }\end{array}$ \\
\hline 1918 & $\begin{array}{l}\text { Grupo Escolar Coelho e } \\
\text { Campos }\end{array}$ & Capela & $\begin{array}{l}\text { General Oliveira } \\
\text { Valadão }\end{array}$ & $\begin{array}{l}\text { Prédio doado pelo ministro } \\
\text { Coelho e Campos }\end{array}$ \\
\hline 1923 & $\begin{array}{l}\text { Grupo Escolar } \\
\text { Gumersindo Bessa }\end{array}$ & Estância & Graccho Cardoso & Construído pelo Estado \\
\hline 1923 & $\begin{array}{l}\text { Grupo Escolar Vigário } \\
\text { Barroso }\end{array}$ & São Cristóvão & Graccho Cardoso & Antiga cadeia da cidade \\
\hline 1923 & $\begin{array}{l}\text { Grupo Escolar General } \\
\text { Valladão }\end{array}$ & Aracaju & Graccho Cardoso & Construído pelo Estado \\
\hline 1924 & $\begin{array}{l}\text { Grupo escolar Sylvio } \\
\text { Romero }\end{array}$ & Lagarto & Graccho Cardoso & Construído pelo Estado \\
\hline 1924 & $\begin{array}{l}\text { Grupo Escolar Dr. } \\
\text { Manuel Luiz }\end{array}$ & Aracaju & Graccho Cardoso & Construído pelo Estado \\
\hline 1925 & $\begin{array}{l}\text { Grupo Escolar José } \\
\text { Augusto Ferraz }\end{array}$ & Aracaju & Graccho Cardoso & $\begin{array}{l}\text { Construído pelo Estado no } \\
\text { terreno doado por Thales Ferraz }\end{array}$ \\
\hline 1925 & $\begin{array}{l}\text { Grupo Escolar Fausto } \\
\text { Cardoso }\end{array}$ & Anápolis ${ }^{1}$ & Graccho Cardoso & Construído pelo Estado \\
\hline 1925 & $\begin{array}{l}\text { Grupo Escolar } \\
\text { Coronel João Fernandes }\end{array}$ & Propriá & Graccho Cardoso & Construído pelo Estado \\
\hline 1925 & $\begin{array}{l}\text { Grupo Escolar } \\
\text { Olympio Campos }\end{array}$ & Vilanova & Graccho Cardoso & Construído pelo Estado \\
\hline 1926 & $\begin{array}{l}\text { Grupo Escolar } \\
\text { Coelho e Campos }\end{array}$ & Capela & Graccho Cardoso & $\begin{array}{l}\text { Permuta de prédio por melhor } \\
\text { acomodação }\end{array}$ \\
\hline 1926 & $\begin{array}{l}\text { Grupo Escolar } \\
\text { Severiano Cardoso² }\end{array}$ & Boquim & Graccho Cardoso & Construído pelo Estado \\
\hline
\end{tabular}

Fonte: mensagens apresentadas pelos presidentes do estado entre 1911 e 1926. APES. Quadro elaborado pelo autor. 
O Quadro I é elucidativo por apresentar o destaque que o governo de Graccho Cardoso atribuiu na disseminação dos grupos escolares. Dos dezesseis prédios entregues a população sergipana entre 1911 e 1926, onze foram inaugurados pelo dito presidente. Se os grupos eram vistos como espaços difusores da modernidade pelo estado de Sergipe, Graccho Cardoso foi o responsável pela consolidação dessas ilhas de civilização. Devemos ressalvar que dois desses grupos inaugurados por Graccho já estavam praticamente conclusos, na ocasião em que assumiu o governo, mesmo assim, o número de obras de sua gestão é bastante significativo. Outro ponto relevante a respeito do quadro é o fato de que esse discurso arquitetônico atribuído à modernidade nem sempre correspondia ao que era posto em prática. Alguns grupos foram instalados em prédios adaptados para tal fim, em decorrência das doações $^{9}$ de prédios e terrenos por lideranças políticas locais. Essa foi uma prática comum tanto em São Paulo como em Sergipe. Podemos enxergar essa prática como uma tentativa de legitimação política, pois o doador benevolente sempre era agraciado com a homenagem na nomenclatura da instituição criada no edifício ${ }^{10}$.

Ainda sobre a readaptação de prédios antigos para funcionarem como grupos escolares são elucidativos os casos dos grupos Barão de Maruim, Silvio Romero e Vigário Barroso. Nos três casos as velhas edificações foram reaproveitadas para a implantação dos grupos. Isso demonstra que o discurso pedagógico modernizador nem sempre foi posto em prática por meio de novos edifícios, mas sim por meio de prédios adaptados para o exercício do magistério. Embora essa constatação pareça contraditória com os propósitos divulgados na imprensa, podemos elucubrar sobre al-

\footnotetext{
9. A prática de doação de prédios e terrenos por políticos para implantação de grupos escolares foi corrente ao longo da Primeira República, pois se tratava de uma forma de construir uma memória de si, de delegar ao futuro a representação de um sujeito benevolente e preocupado com a disseminação do ensino primário, ou seja, era uma estratégia de legitimação político-social. Essa prática foi constatada por pesquisadores dos grupos escolares em outros estados, como Rosa Fátima de Souza (1998) e Luciano Mendes Faria Filho (2000).

10. Em Sergipe os dois casos mais elucidativos são os grupos escolares criados no governo do general Valadão, no terreno e prédio doados respectivamente pelo Barão de Maruim (João Gomes de Mello) e senador José Luiz Coelho e Campos.
}

guns pontos relevantes. No caso do Grupo Barão de Maruim, não existiu um ajustamento estrutural radical, pois no prédio em ruínas já tinha funcionado uma escola, o Asilo Nossa Senhora da Pureza, que foi responsável pela formação de órfãs desvalidas. Já o Grupo Vigário Barroso, instalado no centro histórico da ex-capital, São Cristóvão e o Silvio Romero de Lagarto foram ajustadas a arquitetura dos prédios das antigas cadeias públicas. Além disso, em Anápolis chegou a cogitar-se a implantação do Grupo Escolar Simão Dias na antiga cadeia, que só não foi concretizada em decorrência das condições de higiene. ${ }^{11}$

Isso demonstra que no âmbito arquitetônico educacional, não havia muita distinção entre o prédio escolar e o da prisão ${ }^{12}$. Os dois estavam voltados para condicionar os corpos, para moldar a sociedade à regalia dos anseios do poder, ou seja, pacata e obediente ao Estado e ao patrão. Um elemento simbólico que galgou destaque no cenário educacional e profissional sergipano foi a inserção da sineta ${ }^{13}$ e do relógio, que se tornaram presentes nas escolas e remetiam ao controle das ações educacionais, cronometrando as atividades assim como faziam as sirenes das fábricas. Podemos interpretar a inserção desses instrumentos de controle como uma tentativa de tornar os corpos de alunos obedientes aos ruídos, de se criar uma reação mecânica ao som da sineta.

11. O Grupo Escolar Simão Dias deveria ser instalado no prédio da antiga cadeia pública, que dividia o muro com o cemitério municipal. Isso criou um impasse com as propostas higienistas que buscavam criar as instituições escolares em condições de salubridade. Assim, o grupo foi construído na praça da matriz e inaugurado em 1924. No ano seguinte, por meio do ato de 8 de janeiro de 1925 o grupo teve sua nomenclatura alterada, passando a homenagear o líder republicano de Divina Pastora, Fausto Cardoso. Sobre essas alterações pode ser conferida a obra de Berger (2005).

12. A proximidade entre a escola e o quartel também se torna evidente ao observarmos que o Grupo Escolar General Valladão foi transferido para que seu imponente prédio passasse a abrigar o quartel da polícia militar. Isso implica em afirmar que todo quartel deveria ser visto como quartel e todo quartel também poderia funcionar como escola. O revezamento entre essas instituições pelos prédios públicos majestosos de Sergipe no início do século XX evidencia essa assertiva.

13. Ainda é possível encontrar sinais da cultura material escolar em alguns prédios em que funcionaram os grupos escolares. Um exemplo elucidativo é o Grupo Fausto Cardoso em Simão Dias, no qual ainda podemos visualizar a existência de uma sineta que tinha como atribuição demarcar o tempo escolar. 
Outro dado substancial na compreensão do universo educacional primário sergipano no alvorecer do século XX é em relação as permutas dos prédios escolares, devido a necessidade de se instalar outras instituições, como quartéis policiais e faculdades. Mais uma vez percebemos a proximidade dos prédios de escolas primárias e quartéis, demonstrando que os discursos que comparavam essas duas instituições não estavam construindo uma mera alegoria, mas sim reproduzindo a visão arquitetônica vigente a época. Por essa perspectiva, as cidades que iam edificando seus grupos escolares estavam se guarnecendo, construindo quartéis em que se formariam a infância brasileira, os futuros soldados defensores da nação.

\section{ASAS ABERTAS PARA A RAZÃO: OS EMBATES SOBRE OS GRUPOS}

O governo Graccho Cardoso em sua mensagem de 1925 expôs algumas prerrogativas que estavam sendo atendidas na edificação dos famigerados grupos escolares. Ele aguçou a necessidade de permanecer construindo prédios que atendessem aos critérios científicos, que corroborassem com a tradução do discurso médico nas paredes dos grupos.

\begin{abstract}
Para vos dar uma prova de cuidado do governo no tocante à aposentação das escolas em prédios apropriados, accordes com as leis da hygiene, no que principalmente importa à cubagem do ar indispensável à respiração infantil e à distribuição da luz solar por salões espaçosos, em tudo harmônicos, na proporção rigorosas das dimensões e nos dispositivos guardados acerca do número de creanças freqüentes (SERGIPE, 1925, p. 13).
\end{abstract}

0 aprendizado não era mais uma questão atinente exclusivamente aos professores. Médicos, políticos e engenheiros foram inseridos no leque de discussões a respeito do ensino. Essa constatação reforça a assertiva de Antonio Viñao Frago em relação ao construtor das escolas, ao dizer que "o espaço escolar educa, o arquiteto é um educador (...) e que todo educador tem que ser um arquiteto" (VIÑAO FRAGO, 2001, p. 74). Certamente os engenheiros que estavam encarregados de planejar e acompanhar a construção dos grupos escolares também exerceram essa função pedagógica. Na ereção de uma nova imagem de escola, sob os pressupostos ideológicos da República, foi preciso buscar por uma linguagem que sintetizasse todos os discursos que estavam em voga no momento. Desse modo, os prédios escolares também traziam em si os sinais do higienismo.

Os engenheiros eram atores importantes no cenário de implantação dos grupos. A modernidade pedagógica adentrava no ensino sergipano por meio das inovações arquitetônicas. Uma dessas novidades foi a instalação de sanitários no interior dos prédios escolares, demonstrando que os engenheiros estavam preocupados em tornar o ambiente escolar dentro dos requisitos exigidos pela moderna pedagogia e higienismo. Um sinal dessas adequações apareceu na notícia de inauguração do Grupo Escolar Barão de Maruim, no qual foi destacado o fato de "o estabelecimento sanitário está montado dentro de todas as condições de higiene” (O ESTADO DE SERGIPE, 1917, p. 2).

A necessidade de afirmar que as normas de higiene estavam sendo atendidas demonstra que existiam cobranças a esse respeito. Não eram somente as autoridades que estavam preocupadas em propagar as normas higienistas em Sergipe. Outros setores da sociedade também indagavam sobre a situação. Imprensa, médicos sanitaristas, clero, professores e engenheiros estavam atentos ao universo educacional, além de setores da elite da sociedade sergipana.

Em busca de salubridade e de combate aos miasmas, os engenheiros projetaram prédios e praças que exortavam a modernidade e explicitavam o processo de embelezamento das cidades, substanciada pela medicina higienista. As preocupações com a saúde não permaneceram circunscritas aos prédios escolares. Elas transcenderam para as ruas e praças, com a arborização e criação de jardins, cercados por monumentos que erigiam à memória do Estado.

Podemos perceber que a praça deveria apresentar muitas das prerrogativas médico-higienistas da época. Diferentes memórias eram expostas em meio 
às árvores, arbustos e monumentos. Os poderes de instituições distintas se faziam presentes. 0 discurso higienista aparecia por meio da pavimentação, das árvores e, principalmente, dos jardins. A República se fez mostrar, mas não sozinha. Ela emergiu no cenário público trazendo consigo as tensões e ansiedades de seu tempo, reconstruindo a identidade nacional sob os requisitos da higiene, modernidade e educação.

Em outras palavras, a formação da infância sergipana foi pensada dentro dos parâmetros da cultura política vigente no terceiro decênio do século XX. O conceito de cultura política tem contribuído de forma significativa na reformulação dos estudos históricos, pois possibilita a compreensão do político mais que político, ou seja, "supre ao mesmo tempo uma leitura comum do passado e um projeto no futuro vivido em conjunto" (BERSTEIN, 1998, p. 352). Desse modo, pode-se inferir que nos três primeiros decênios do século XX constituiu-se uma cultura política educacional republicana, na qual a educação da infância nacional era entendida como um princípio a ser conquistado pelas lideranças políticas atreladas ao novo regime, no intuito de solucionar os déficits educacionais do período imperial. $\mathrm{Na}$ ótica dos políticos republicanos, a educação primária seria o elemento primordial na consolidação do novo regime e na construção da democracia.

Os grupos escolares construídos nessa época foram marcados por tais preocupações. Por ser um espaço público de grande movimentação de pessoas, era necessário observar as questões de higiene para evitar problemas como a disseminação de doenças. Em 1926 Graccho Cardoso reforçou a necessidade de criar escolas seguindo os pressupostos do higienismo.

A objeção feita sobre o curso dos grupos e a organização das classes pouca attenção merece, porquanto é dever da administração cuidar do bem-estar e zelar pela saúde e commodidade dos alumnos, dando-lhes edifícios hygienicos, salões amplos e arejados, onde a luz penetre discretamente e que dispunham de mobiliário moderno e apparelhamento próprio para o bom funccionamento das aulas (SERGIPE, 1926, p. 18).
Os preceitos do higienismo aparecem na descrição realizada por Graccho Cardoso. 0 presidente do estado reforçou a idéia de que era necessário construir prédios que atendessem aos anseios do período. Para tanto, os engenheiros foram obrigados a inserir no grupo escolar elementos que afastassem o risco de epidemias entre os alunos e professores. 0 principal deles foi o porão. Muitos dos prédios construídos entre 1911 e 1926 foram edificados com porões, o que os tornavam mais imponentes nas vias públicas de suas cidades. A exceção ficou para os prédios em que ocorreram doações ou apenas pequenas adaptações da estrutura anterior, como o Grupo Escolar Coelho e Campos de Capela, o Grupo Escolar Vigário Barroso de São Cristóvão e o Grupo Escolar Olímpio Campos em Vilanova ${ }^{14}$.

O uso dos porões nas edificações educacionais era de importância crucial, pois se tratava de uma forma de manter o piso da escola afastado da frieza do solo, principalmente na cidade de Aracaju, que foi planejada para ser construída sobre os lamaçais de pântanos e riachos ${ }^{15}$. Foi na capital sergipana que os porões tiveram maior visibilidade, criando uma imagem de escola que se afastava da população por sua imponência, altivez e riqueza dos detalhes. Os porões

14. Segundo Miguel André Berger o Grupo Escolar Olimpio Campos de Vilanova teve de ser transferido de seu prédio original para a Igreja Nossa Senhora do Rosário, na praça da matriz e foi muito criticado pela população devido ao estado precário em que se encontrava (BERGER, 2005, p. 76). Como já foi apresentada anteriormente, a prática de transferência das sedes dos grupos escolares foi corrente no período em foco, seja por motivos oriundos da criação de novas instituições, seja pelas inadequações pedagógicas dos prédios em que funcionavam. Além de Vilanova, esse episódio ocorreu em Capela e Aracaju, como atesta a documentação referente aos estabelecimentos escolares produzidos entre 1911 e 1926. Todavia, o caso de Vilanova ainda é duvidoso.

15. O caso de Aracaju assemelha-se ao do Rio de Janeiro nos últimos decênios do século XIX, que também sofria com os problemas oriundos dos miasmas, das condições precárias de higiene que tornavam o ensino torpe, inadequado aos anseios sociais. A capital sergipana sofria com graves problemas de saneamento em decorrência da inexistência de pavimentação e da exuberância de rios, riachos e manguezais que cortavam a cidade. Segundo Gondra, a Corte era descrita no final do Império "como um imenso anfiteatro, como um vasto receptáculo de umidade, dando um solo apodrecido em águas estagnadas, em lodaçais desprezados e, alguns, até conservados. Além disso, (...) os antigos colonos mergulharam choças e casebres dessa antiga cidade entre morros e desvios" (GONDRA, 2007, p. 529). 
contribuíram para esse distanciamento, ao passo que tornavam os prédios mais vistosos ${ }^{16}$. Observe a fachada do Grupo Escolar Dr. Manuel Luiz, na Figura I:

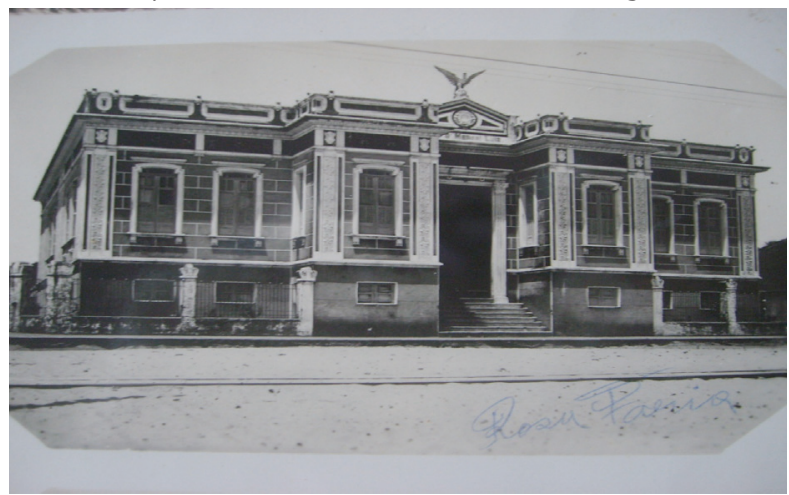

Figura I: Grupo Escolar Dr. Manuel Luís. Fonte: Acervo Iconográfico Rosa Faria. Memorial de Sergipe RFI 00200048-2

Muitas vezes, os porões nos prédios escolares apareciam apenas como elemento alegórico, para tornar a construção mais elevada e realçada no cenário urbano. Os grupos eram a tradução dos novos tempos republicanos na esfera educacional. 0 prédio inaugurado por Graccho Cardoso para servir como segunda sede do Grupo Escolar Coelho e Campos em Capela refletia essa busca pela imponência, pois havia um falso porão.

Os entraves republicanos também transpareciam nas imagens dos grupos. A arquitetura imponente foi uma forma de violência simbólica no seio dos núcleos urbanos sergipanos, pois em meio a um casario rústico e ruas sem pavimentação e condições dignas de higiene emergiam magníficos edifícios com o intuito de ser escola, de demonstrar o poderio de um regime que acabara de nascer.

16. Para Rosa Fátima de Souza, uma das atribuições dos grupos escolares era a visibilidade, apresentando à população os princípios de higiene, civilidade e estética, pois "os edifícios dos primeiros grupos escolares puderam sintetizar todo o projeto político atribuído à educação popular: convencer, educar, dar-se a ver" (SOUZA, 1998, p. 123).
As contradições republicanas foram expressas na linguagem arquitetônica. Eram prédios grandiosos, com fachadas imponentes e elevadas sobre os porões, que os tornavam distantes da realidade vivenciada pelo público que deveria atender. Enquanto os governantes vangloriavam as benesses de possuir prédios com escadarias prodigiosas que elevariam a civilização, a maior parte da infância sergipana perambulava descalça pelas ruas sem pavimentação das cidades do estado. No mesmo passo em que os edifícios soerguiam nas ruas centrais da capital e das cidades importantes do interior, a população vivia à margem dos acontecimentos, em casebres que em nada remetiam à modernidade expressa nos depoimentos e mensagens presidenciais. Assim como a República, os grupos escolares eram excludentes, pois não atendiam a todos.

\section{REFERÊNCIAS}

BENCOSTTA, Marcus Levy Albino. “Desfiles Patrióticos: Memória e Cultura Cívica dos Grupos Escolares de Curitiba (1903-1971)”. In: VIDAL, Diana Gonçalves (org). Grupos Escolares: Cultura escolar primária e escolarização da infância no Brasil (1893-1971). São Paulo: FAPESP/ Mercado das Letras, 2006.

BERGER, Miguel André. "A Prática pedagógica e avaliativa no cotidiano dos grupos escolares". In: NASClMENTO, Jorge Carvalho do. Problemas de educação escolar e extra-escolar. São Cristóvão-SE; Editora UFS, 2005, p. 63-100.

BERGER, Miguel André. . A instrução primária em Sergipe na era da modernidade: analisando a trajetória dos grupos escolares. São Cristóvão. 2006. 29 f. Relatório (Pesquisa Fap/CNPq). UFS.

BERSTEIN, Serge. A cultura política. In: RIOUX, JeanPierre; SIRINELLI, Jean-Francois. Para uma História cultural. Lisboa: Estampa, 1998. 
BUFFA, Ester \& PINTO, Gelson de Almeida. Arquitetura e Educação: organização do espaço e propostas pedagógicas dos grupos escolares paulistas. 1893- 1971. São Carlos- SP: Brasília: EDUFSCAR, INEP, 2002.

BURKE, Peter. Testemunha Ocular: História e imagem. Tradução Vera Maria Xavier dos Santos. Bauru-SP: EDUSC, 2004.

CABRAL, Mário. Roteiro de Aracaju. $3^{a}$ Ed. Aracaju: Banese, 2002.

CARVALHO, José Murilo de. A construção da ordem: a elite política imperial. Rio de Janeiro: UFRJ/ Relume-Dumá, 1996.

CHARTIER, Roger. A História Cultural: entre práticas e representações. Lisboa: DIFEL, 1990.

ELIAS, Norbert. 0 Processo Civilizador: uma História dos Costumes. Vol. 1. Trad. Ruy Jungmann. Rio de Janeiro: Jorge Zahar, 2008.

ESCOLANO, Agústin. "Arquitetura como programa: espaço-escola e currículo”. In: Currículo, espaço e subjetividade: a arquitetura como programa. Trad. Alfredo Veiga Neto. $2^{\mathrm{a}}$ ed. Rio de Janeiro: DP \& A, 2001.

FARIA FILHO, Luciano Mendes de. Dos Pardieiros aos Palácios: cultura escolar e urbana em belo Horizonte na Primeira República. Passo Fundo: UFP, 2000.

GINZBUG, Carlo. Sinais, raízes de um paradigma indiciário. In: Mitos, Emblemas, Sinais: morfologia e História. Trad. Frederico Carotti. São Paulo: Companhia das Letras, 1989.

LE GOFF, Jacques. História e Memória. $5^{\text {a }}$ ed. Campinas-SP: Ed. da UNICAMP, 2003.

LEVI, Giovanni. A Herança Imaterial: carreira de um exorcista no Piemonte do século XVII. Rio de Janeiro: Civilização Brasileira, 2000.
MONARCHA, Carlos "Arquitetura escolar republicana: a Escola Normal da Praça e a construção de uma imagem de criança”. In: FREITAS, Marcus Cezar de. História Social da Infância no Brasil. $5^{a}$ ed. São Paulo: Cortez, 2003, p. 101-140.

NASCIMENTO, Jorge Carvalho do. "A escola no espeIho: São Paulo e a implantação dos grupos escolares no Estado de Sergipe”. In: VIDAL, Diana (org). Grupos Escolares. Cultura escolar primária e escolarização da infância no Brasil (1893-1971). Campinas-SP. Mercado das Letras, 2006. p. 153-172.

NORA, Pierre. Entre memória e história: a problemática dos lugares. In: Projeto História: História e cultura. São Paulo: Editora da PUC, 1981, p. 7-28.

NUNES, Maria Thetis. História da Educação em Sergipe. Rio de Janeiro: Paz e Terra, 1984.

SANTOS, Magno Francisco de Jesus. Além do Silêncio: espaço, arquitetura e educação no Grupo Escolar Barão de Maroim. São Cristóvão, 2005. 113 f. Monografia (Licenciatura em História). DHI, CECH, UFS.

SANTOS, Magno Francisco de Jesus. Ecos da Modernidade: a arquitetura dos grupos escolares sergipanos (1911-1922). São Cristóvão: EDUFS, 2013.

PINHEIRO, Antônio Carlos Ferreira. Da era das cadeiras isoladas a era dos grupos escolares na Paraiba. Campinas, SP: Autores associados, São Paulo: Universidade São Francisco, 2002.

SERGIPE. Mensagem do presidente do estado de Sergipe Maurício Graccho Cardoso dirigida a Assembléia Legislativa de Sergipe em 07 de setembro de 1924, ao instalar a $2^{\mathrm{a}}$ sessão Ordinária da $15^{\mathrm{a}}$ Legislatura. Aracaju: Imprensa Official, 1924. APES, Diversos Sergipe, Mensagens. Cx. 05, doc. 06, vol. 85.

SERGIPE. Mensagem do presidente do estado de Sergipe Maurício Graccho Cardoso dirigida a As- 
sembléia Legislativa de Sergipe em 07 de setembro de 1925, ao instalar a $3^{a}$ sessão Ordinária da $15^{a}$ Legislatura. Aracaju: Imprensa Official, 1925. APES, Diversos Sergipe, Mensagens. Cx. 05, doc. 07, vol. 86.

SERGIPE. Mensagem do presidente do estado de Sergipe Maurício Graccho Cardoso dirigida a Assembléia Legislativa de Sergipe em 07 de setembro de 1926 , ao instalar a $1^{\text {a }}$ sessão Ordinária da $16^{a}$ Legislatura. Aracaju: Imprensa Official, 1926. APES, Diversos Sergipe, Mensagens. Cx. 05, doc. 08, vol. 87.

SOUZA, Rosa Fátima de. Templos de Civilização: a implantação da escola primária graduada no Estado de São Paulo (1889-1910). São Paulo: Ed. da UNESP, 1998.
VIDAL, Diana Gonçalves. Culturas Escolares: estudo sobre práticas de leitura e escrita na escola pública primária (Brasil e França, final do século XIX). Campinas-SP: Autores Associados, 2005.

VIÑAO FRAGO, Antonio. "Do espaço escolar e da escola como lugar: propostas e questões”. In: Currículo, espaço e subjetividade: a arquitetura como programa. Trad. Alfredo Veiga Neto. $2^{\mathrm{a}}$ ed. Rio de Janeiro: DP \& A, 2002.

VIÑAO FRAGO, Antonio.. El espacio y El tiempo escolares como objeto históricos. In: Contemporaneidade e Educação. № 7. Rio de Janeiro: IEC, 2000. p. 100101.

VIÑAO FRAGO, Antonio. Tiempos Escolares, tiempos sociales: la distribución del tiempo e del trabajo en la enseñanza primaria en España (1838-1936). Barcelona: Ariel, 1998. 